\title{
Adsorption of Toluene on Film Membranes of Chitosan/Na-CMC
}

\author{
Abdullaev Nodirkhon Juraxonovich, Kodirkhonov Murodkhon Rashidhonovich \\ Namangan State University, Namangan City, Uzbekistan \\ Email: kodirkhonov@mail.ru
}

How to cite this paper: Juraxonovich, A.N and Rashidhonovich, K.M. (2021) Adsorption of Toluene on Film Membranes of Chitosan/Na-CMC. Advances in Biological Chemistry, 11, 296-301.

https://doi.org/10.4236/abc.2021.116020

Received: November 2, 2021

Accepted: December 20, 2021

Published: December 23, 2021

Copyright () 2021 by author(s) and Scientific Research Publishing Inc. This work is licensed under the Creative Commons Attribution International License (CC BY 4.0).

http://creativecommons.org/licenses/by/4.0/

\begin{abstract}
The sorption properties of films on bases of chitosan and sodium carboxyl methylcellulose (Na-CMC) with toluene have been checked. The sorption rate, sorption thermodynamics and isothermal properties of toluene molecules in chitosan/Na-CMC films are analyzed by adsorption-calorimetric method. Thus, it was found that toluene is adsorbed on the chitosan/Na-CMC film by the same patterns of sorption of aromatic compounds, due to the process of penetration of toluene molecules into the network of chitosan macromolecules and this is preceded by the absorption process by the surface of the chitosan/Na-CMC film.
\end{abstract}

\section{Keywords}

Chitosan, Sodium Carboxyl Methylcellulose (Na-CMC), Toluene, Film-Membrane, Adsorption-Calorimetric Method, Adsorption

\section{Introduction}

Nowadays, the development of the chemical industry results in a negative impact on the environment. Toxic substances in the wastewater of the oil refining industry and petrochemical factories alone are leading to a deterioration of the ecological situation. One of the environmental problems that worry the whole world is the pollution of drinking and sewerage networks. Therefore, to solve this problem, a number of studies and practical work are being carried out.

Chitosan and its modifications are widely used for the sorption of various organic compounds and metal ions. For example, the work [1] involves bunch experiments to investigate the effect of contact time, $\mathrm{pH}$, and adsorbent dose on the extent of adsorption by bio-composites. Adsorption capacity of Chromium (VI) onto chitosan coated with banana and areca fiber was investigated in a batch system by considering the effects of various parameters like contact time, initial 
concentration, $\mathrm{pH}$ and adsorbent dose. The chitosan and fibers (banana and areca) were then cross-linked with glutaraldehyde to remove chromium [Cr (VI)] from water via static adsorption.

In particular, Singaporean scientists Nai Naing and Sam Fong [2] conducted studies on the use of the sorption properties of the polysaccharide chitosan and complexes based on glutaraldehyde for the purification of organic substances (benzene, toluene, ethylbenzene, xylene and styrene) from wastewater. Giffin and Davis conducted research on the use of polysaccharides for the purification of toluene from water in oil refining [3].

In this study, interpolymer complexes were formed with the presence of $\mathrm{Na}$ salt of chitosan and carboxymethylcellulose [4]. The sorption properties of the obtained films were tested on the basis of experiments conducted in a high-vacuum adsorption device.

The main purpose of our research is to study the effects of aromatic compounds containing radical groups on the surfaces of polymer sorbents and the laws of sorption processes, as well as the analysis of the sorption-structural state.

Used for investigations the chitosan obtained from silkworm Bombyx Mori. $\mathrm{Na}-\mathrm{CMC}$ was obtained from cotton cellulose which was manufactured in "Carbonam" LTD.

The adsorption experiments are carried out in a universal high-vacuum system with a U-monometer and a completed to this system Tiana-Kalve differential microcalorimeter for measuring differential temperatures and isotherm of adsorption.

\section{Results and Discussion}

The adsorption isotherms of toluene on the chitosan/Na-CMC film membrane are shown in Figure 1 in logarithmic coordinates. The adsorption isothermal line of toluene on the chitosan/Na-CMC film membrane shows that the relative pressure of the initial adsorbate molecules is $\mathrm{P} / \mathrm{P}_{0}=0.0004$, the atmospheric pressure is 0.0485 , the isotherm logarithm is $\ln \left(\mathrm{P} / \mathrm{P}_{0}\right)=-6.63$ and the adsorbents. The amount is $0.008 \mathrm{mmol} / \mathrm{g}$.

When calculating the adsorption isotherm of toluene on the chitosan/Na-CMC film membrane, the values of pressure at equilibrium are obtained. Equilibrium pressure is determined using a U-shaped monometer of a high-vacuum adsorption device. Experiments on this device are carried out mainly using absolutely pure adsorbents. In experimental work, a U-shaped manometer is continuously measured until the pressure reaches a constant value. Undetermined values on the U-monometer are measured on the McLeod part of the device. Measurements are made on the macro until the U-monometer reaches $0.1 \mathrm{~mm}$ of mercury. The value obtained is divided by the saturated vapor pressure of toluene at $303 \mathrm{~K}$ $(36.7 \mathrm{mmHg})$ and the natural logarithmic value $\ln \left(\mathrm{P} / \mathrm{P}_{0}\right)$ is obtained. The main difference in the adsorption of toluene from benzene is that the initial bonding in toluene is mainly due to methyl groups. Due to the presence of a methyl group, its molecular size is larger than that of benzene. 


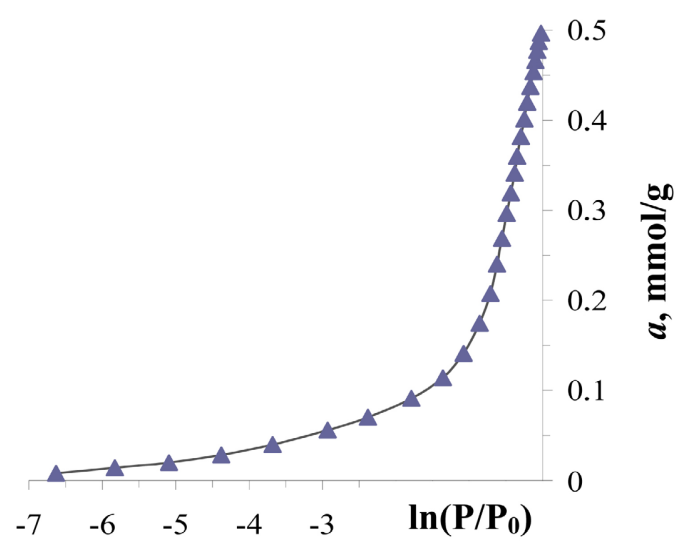

Figure 1. Chitosan/Na-CMC toluene adsorption isotherm at film membrane at $303 \mathrm{~K}$.

It is known from the graph of the adsorption of toluene molecules on the membrane of chitosan/Na-CMC that the adsorption isotherm increases gradually.

In the processes that take place on the surface, mainly adsorption isotherms form an arc shape. Toluene molecules combine by hydrogen bonding with amino, hydroxide, and carboxyl groups in the sorbent. When the adsorption reaches $0.1 \mathrm{mmol} / \mathrm{g}$, the isotherm is -1.36 . After $0.1 \mathrm{mmol} / \mathrm{g}$, the changes in isothermal values gradually decrease. The isothermal lines rise vertically and slowly approach the axis of adsorption (ordinate). When the adsorption reaches $0.5 \mathrm{mmol} / \mathrm{g}$, the isotherm value is -0.02 .

The differential heat of toluene adsorption on the chitosan/Na-CMC membrane film is shown in Figure 2. The differential heat of adsorption has a straight-line curvilinear appearance. For the initial toluene molecule adsorption, the adsorption rate is $0.004 \mathrm{mmol} / \mathrm{g}$, while the differential heat of the absorbed toluene molecule is $41.21 \mathrm{~kJ} / \mathrm{mol}$, generating the maximum heat. The heat for subsequent adsorption of the toluene molecule is $39.79 \mathrm{~kJ} / \mathrm{mol}$. The heat of adsorption decreases in the form of waves, which also forms specific peaks. The adsorption heat is $39.66 \mathrm{~kJ} / \mathrm{mol}$, forming the first step from $0.011 \mathrm{mmol} / \mathrm{g}$ to $0.048 \mathrm{mmol} / \mathrm{g}$ and the second step from $0.048 \mathrm{mmol} / \mathrm{g}$ to $0.102 \mathrm{mmol} / \mathrm{g}$. After $0.1 \mathrm{mmol} / \mathrm{g}$, toluene is adsorbed on the chitosan film membrane.

Starting from the third step, chitosan/Na-CMC are adsorbed on the film membrane by toluene molecules. It ranges from $0.102 \mathrm{mmol} / \mathrm{g}$ to $0.191 \mathrm{mmol} / \mathrm{g}$ and is $38.49 \mathrm{~kJ} / \mathrm{mol}$. In the fourth stage, the range is from $0.191 \mathrm{mmol} / \mathrm{g}$ to 0.283 $\mathrm{mmol} / \mathrm{g}$, and the adsorption heat is $37.44 \mathrm{~kJ} / \mathrm{mol}$. From the third step, a decrease in the adsorption heat is observed. The difference between the adsorption heat in the third and fourth stages is $1 \mathrm{~kJ} / \mathrm{mol}$.

The fifth step goes in the range of $0.28 \mathrm{mmol} / \mathrm{g}$ to $0.371 \mathrm{mmol} / \mathrm{g}$. The heat of adsorption decreases from $37.44 \mathrm{~kJ} / \mathrm{mol}$ to $36.66 \mathrm{~kJ} / \mathrm{mol}$. In the sixth stage, a range of $0.317 \mathrm{mmol} / \mathrm{g}$ to $0.424 \mathrm{mmol} / \mathrm{g}$ is formed, in which $0.053 \mathrm{mmol} / \mathrm{g}$ toluene is sorbed. The adsorption heat decreases from $36.66 \mathrm{~kJ} / \mathrm{mol}$ to $35.21 \mathrm{~kJ} / \mathrm{mol}$. The decrease in thermal adsorption is explained by the decrease in adsorption 


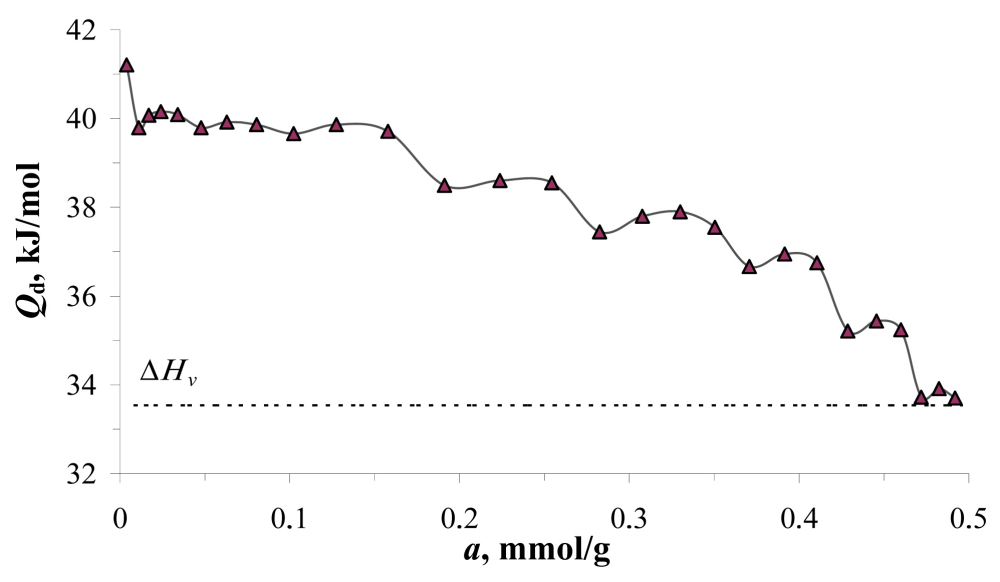

Figure 2. Chitosan/Na-CMC at $303 \mathrm{~K}$ Differential heat of toluene adsorption on the film membrane: horizontal bar-heat of condensation of toluene.

energy as a result of saturation of the active centers of the toluene chitosan/NaCMC film membrane. A decrease in adsorption energy is also observed experimentally. In this case, a decrease in condensation time, a decrease in the surface values of adsorbents sorbed on the adsorbate surface in the potentiometer part of the device relative to the initial sorption values.

In the seventh stage, the adsorption heat decreases from $35.21 \mathrm{~kJ} / \mathrm{mol}$ to 33.72 $\mathrm{kJ} / \mathrm{mol}$ and $0.048 \mathrm{mmol} / \mathrm{g}$ toluene is absorbed. Adsorption ranged from 0.424 $\mathrm{mmol} / \mathrm{g}$ to $0.472 \mathrm{mmol} / \mathrm{g}$. After $0.472 \mathrm{mmol} / \mathrm{g}, 0.02 \mathrm{mmol} / \mathrm{g}$ toluene is adsorbed at the end of the process and the heat goes very close to the condensation line.

Chitosan/ $\mathrm{Na}-\mathrm{CMC}$ are sorbed into the membrane film by $0.8 \mathrm{mmol} / \mathrm{g}$ toluene.

According to the Gibbs equation, the differential molar entropy of toluene adsorption on the chitosan/Na-CMC membrane film was determined $\Delta S_{\mathrm{d}}$, where the entropy of liquid toluene was assumed to be zero.

According to the Gibbs-Helmholtz equation, the differential molar entropy $\Delta S_{\mathrm{d}}$ of toluene adsorption on the chitosan/Na-CMC membrane film was calculated (assuming that the entropy of liquid toluene was zero).

Figure 3 shows the differential entropy of adsorption of chitosan/Na-CMC film membrane toluene molecules at $303 \mathrm{~K}$. Initially, the adsorption entropy of toluene molecules is $32.11 \mathrm{~J} / \mathrm{mol} \cdot \mathrm{K}$. The initial toluene molecules interact with the functional groups on the surface of the resulting interpolymer film membrane and are higher than the standard state entropy value, which is explained by the sorption of chitosan/Na-CMC on the film surfaces. This adsorption process continues until it reaches $0.06 \mathrm{mmol} / \mathrm{g}$.

After $0.06 \mathrm{mmol} / \mathrm{g}$, the movement of toluene molecules is partially limited as a result of the interaction of chitosan/Na-CMC with functional groups inside the chemical bond chains that form the film membrane. Therefore, the standard case is below the entropy value.

We obtained the standard entropy of the liquid state of toluene as $0 \mathrm{~J} / \mathrm{mol} \cdot \mathrm{K}$. When the toluene molecules are then adsorbed, the entropy values decrease to the standard state entropy. 


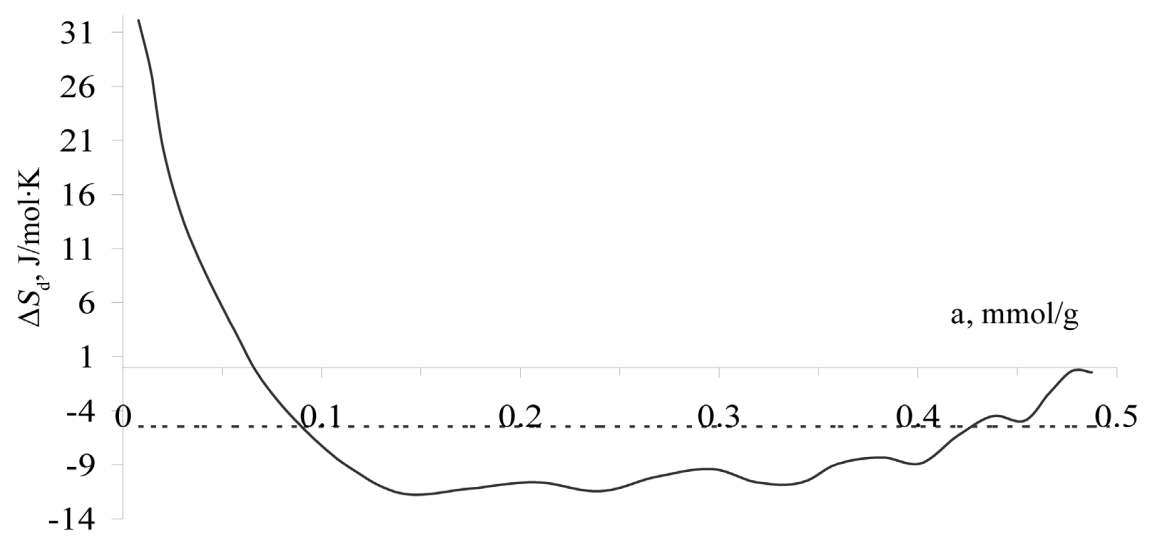

Figure 3. Entropy of adsorption of toluene molecule on the membrane of Chitosan/Na$\mathrm{CMC}$ at $303 \mathrm{~K}$ : horizontal bar line-average molar integral entropy; the entropy of liquid toluene was assumed to be zero.

When the adsorption amount of the next toluene molecule reaches $0.15 \mathrm{mmol} / \mathrm{g}$, the entropy is $-11.5 \mathrm{~J} / \mathrm{mol} \cdot \mathrm{K}$, which is smaller than the average integral entropy. When the adsorption reaches $0.4 \mathrm{mmol} / \mathrm{g}$, the entropy value is $-8.87 \mathrm{~J} / \mathrm{mol} \cdot \mathrm{K}$. In the range of $0.1 \mathrm{mmol} / \mathrm{g}$ to $0.42 \mathrm{mmol} / \mathrm{g}$, entropy values are below average integral entropy values.

This can be seen from the entropy graph. The average integral entropy of toluene adsorption on the membrane of chitosan/Na-CMC is $5.47 \mathrm{~J} / \mathrm{mol} \cdot \mathrm{K}$. Adsorption ranges from $0.07 \mathrm{mmol} / \mathrm{g}$ to $0.48 \mathrm{mmol} / \mathrm{g}$ are below the standard state entropy value. In $86 \%$ of the chitosan/ $\mathrm{Na}-\mathrm{CMC}$ film membrane, toluene molecules are partially undissolved. Adsorption is relatively constant in the range of $0.141 \mathrm{mmol} / \mathrm{g}$ to $0.401 \mathrm{mmol} / \mathrm{g}$, i.e. the average value is $11.02 \mathrm{~J} / \mathrm{mol} \cdot \mathrm{K}$. These values, in turn, indicate the interaction of chitosan/ $\mathrm{Na}-\mathrm{CMC}$ with a single family of functional groups.

Entropy values indicate that the adsorption of toluene molecules on chitosan/CMC is stronger than that of chitosan.

Figure 4 shows the equilibrium time (thermokinetics) of toluene adsorption on the film membrane of chitosan/Na-CMC. The initial equilibrium time is 1.8 hours.

During subsequent adsorption of toluene molecules, the equilibrium time lines gradually decrease in a wavy manner, and the equilibrium time of the previously sorbed adsorbate decreases by $20 \mathrm{~min}$. The adsorption rate is reduced to 0.15 $\mathrm{mmol} / \mathrm{g}$ and the thermokinetic time is reduced to 1.5 hours. After $0.37 \mathrm{mmol} / \mathrm{g}$, the adsorption equilibrium time accelerates slightly, and the equilibrium time required for the saturation of the chitosan/Na-CMC film membrane with toluene molecules is $5 \mathrm{~min}$.

In the work [5] the sorption properties of the chitosan film for benzene was studied and found that the adsorption of benzene on the chitosan film membrane has a constant value of $0.008-0.4 \mathrm{mmol} / \mathrm{g}$ in the range of differential heat of adsorption $40.0-40.8 \mathrm{~kJ} / \mathrm{mol}$. 


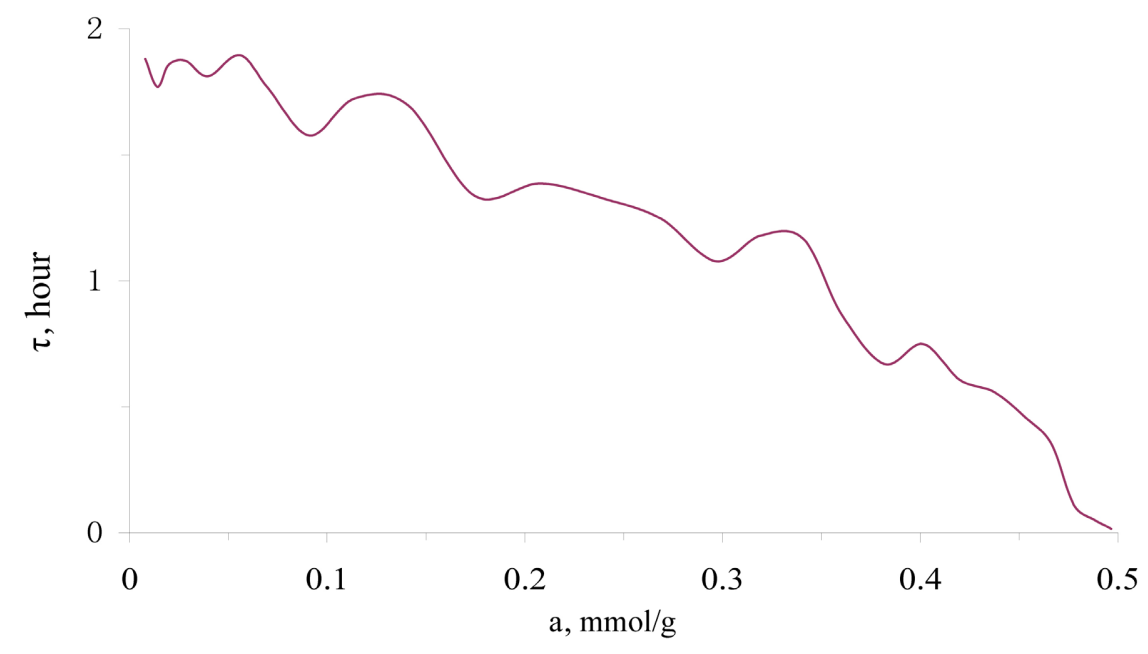

Figure 4. Chitosan/Na-CMC at $303 \mathrm{~K}$ are the equilibrium time of adsorption of the toluene molecule on the membrane film.

\section{Conclusion}

Thus, it was found that toluene is adsorbed on the chitosan/Na-CMC film by the same patterns of sorption of aromatic compounds, due to the process of penetration of toluene molecules into the network of chitosan macromolecules and this is preceded by the absorption process by the surface of the chitosan/Na-CMC film.

\section{Conflicts of Interest}

The authors declare no conflicts of interest regarding the publication of this paper.

\section{References}

[1] Begum, H., Haque, A., Islam, M., Hasan, M., Ahmed, S., Razzak, M. and Khan, R. (2020) Analysis of the Adsorption of Toxic Chromium (VI) by Untreated and Chitosan Treated Banana and Areca Fiber. Journal of Textile Science and Technology, 6, 81-106. https://doi.org/10.4236/jtst.2020.62007

[2] Naing, N. and Fong, S. (2016) Application of Porous Membrane-Protected Chitosan Microspheres to Determine Benzene, Toluene, Ethylbenzene, Xylenes and Styrene in Water. Journal of Chromatography A, 1448, 42-48. https://doi.org/10.1016/j.chroma.2016.04.062

[3] Giffin, S.D. and Davis, A.P. (1998) Prediction of Carbon BTEX Adsorption Capacity Using Field Monitoring Data. Journal of Environmental Engineering, 124, 921-931. https://doi.org/10.1061/(ASCE)0733-9372(1998)124:10(921)

[4] Xu, Q., Chen, C., Rosswurm, K., Yao, T. and Janaswamy, S. (2016) A facile route to prepare cellulose-based films. Carbohydrate Polymers, 149, 274-281. https://doi.org/10.1016/j.carbpol.2016.04.114

[5] Абдуллаев, Н.Ж., Кодирхонов, М.Р. and Эргашев, О.К. (2021) Адсорбция бензола на хитозановой пленке. Universum: химия и биология.

https://7universum.com/ru/nature/archive/item/12352 